Article

\title{
Governance in the Arts and Culture Nonprofit Sector: Vigilance or Indifference?
}

\author{
Johanne Turbide * and Claude Laurin \\ Department of Accounting Studies, HEC Montréal, 3000 Côte-Sainte-Catherine Road, \\ Montréal, QC H3T 2A7, Canada; E-Mail: claude.laurin@hec.ca \\ * Author to whom correspondence should be addressed; E-Mail: johanne.turbide@hec.ca; \\ Tel.: +1-514-340-6555; Fax: +1-514-340-6630.
}

External Editor: Mary Tschirhart

Received: 4 July 2014; in revised form: 23 September 2014 / Accepted: 11 October 2014 / Published: 13 November 2014

\begin{abstract}
In this article we attempt to contribute to governance research in the nonprofit area by proposing a conceptual framework inspired by recent developments in the literature. First, we analyze the governance of nonprofit organizations (hereafter, NPOs) from different theoretical perspectives, inspired by for-profit, nonprofit and public sector theories on governance. After presenting a governance framework for NPOs, we explore empirically whether its various dimensions are being taken into account by NPOs in the arts and culture sector. Our findings suggest that, among NPOs in this sector, governance is still viewed as a narrow concept where board members are mainly passive, basically rubber-stamping decisions for the benefit of external funders.
\end{abstract}

Keyword: governance; non-profit organizations; arts management; governance framework

\section{Introduction}

The last 15 years have seen a growing body of literature on governance in both the for-profit and nonprofit sectors [1-4]. During recent financial crises, and because of the scandals that were feeding them, the role played by board members to prevent crises and scandals has come under intense scrutiny. Since the start of the crises, the literature on governance has proliferated and different theories and 
models have been developed, most aimed at providing a better understanding of the ways in which good governance could help prevent such crises in the future [5].

In this article we attempt to contribute to the governance research in the nonprofit area by proposing a framework inspired by recent developments in the literature. First, we analyze the governance of nonprofit organizations (hereafter, NPOs) from different theoretical perspectives, inspired by for-profit, nonprofit and public sector theories on governance. After presenting a conceptual framework to analyze the governance of NPOs, we use the various dimensions of the framework to document if they are being taken into account by a sample of NPOs in the arts and culture sector. Our research question is as follows: How do NPOs in the arts and culture sector incorporate external and internal dimensions into their governance practices? Our findings suggest that, among NPOs in this sector, governance is still viewed as a narrow concept where board members are mainly passive, basically rubber-stamping decisions for the benefit of external funders.

\section{Literature Review}

A growing body of literature on governance in NPOs posits that, due to the different external and internal contexts in which nonprofit and for-profit organizations operate, the for-profit governance model, mostly inspired by agency theory, is not effective for NPO governance [2,6-8]. Ostrower and Bobowick [9] reports that the Sarbanes-Oxley Act—aimed at regulating governance in publicly traded firms through different mandatory practices - should not be applied directly to nonprofit institutions without acknowledging the impact, cost and inherent values in NPOs of different types and sizes.

Another stream of research is aimed at developing improved governance practices for NPOs. Contributions in this area focus on the roles and responsibilities of board members [10-12] and relationships between board members and staff [13,14]. This stream of research includes normative papers on how to uncover the "best way" to govern and empirical papers aimed at documenting how governance works in the "real world" [15-17]. These two types of research have been very useful for understanding the specifics of NPO governance.

However, among experts $[3,5,8,18]$ there is growing concern that these studies, which are mainly normative or descriptive in nature, do not describe the specific mechanisms of nonprofit governance [8]. Cornforth [1] suggests that the various theoretical perspectives - for example, agency theory, resource dependence theory, stakeholder theory, stewardship theory, managerial hegemony theory-be analyzed simultaneously, from a multi-paradigm perspective, in order to capture the complexity of organizational realities faced by NPOs. Cornforth [1] also acknowledges the need to compare recent developments in for-profit, nonprofit and public sector governance in order to first identify similarities and differences among these different types of organization and then see what is relevant across types [1] (p. 6). In the same vein, Ostrower and Stone [18] suggest the following:

Despite the legitimate focus on governance at the organizational level of analysis, we argue that nonprofit scholars must widen their scope of inquiry. First, boards as well as the nonprofits they govern increasingly find themselves within regimes of public governance that directly affect them [18] (p. 426). 
In a recent research paper, Ostrower and Stone [5] develop a contingency-based framework in line with Kramer's [19] argument that "a unitary model of board-executive relationships is inadequate because those relationships vary depending on a host of internal and external variables" [19] (p. 902). Subsector, size, CEO tenure, regulations, funding sources, type of financial dependence, regulations, and external stability are among the variables that can affect NPO governance.

Based on these significant contributions to the literature, we propose a conceptual framework that takes into account the developments of governance in the different economic sectors (for-profit, nonprofit, public) and the organization's external and internal dimensions, size and subsector. This framework was built as a result of a vast research project we undertook in 2006, aimed at helping NPOs in the arts and culture sector prevent financial crises [20]. Interacting with both the federal (Canada) and provincial (Quebec) governments, we attempted to identify the main factors driving the financial difficulties encountered by several NPOs in the arts and culture sector. Our analysis of different organizations facing a crisis led us to two preliminary conclusions. First, the lack of artistic success is not the principal cause of financial distress, as many arts and culture NPOs facing a major financial crisis were viewed as successful by their main stakeholders, their public and their funders. Second, NPOs in financial distress have weak governance, a conclusion supported by two facts: their board members were not aware of the problem leading to the crisis, and CEOs had no choice but to request emergency funds from governments [21].

As a result of this first diagnostic of the causes of financial crisis, we were interested in documenting governance practices in arts and culture NPOs using an integrative framework that would take into account external and internal dimensions of the organization's environment. More precisely, we wanted to examine; how do NPOs in the arts and culture sector incorporate external and internal dimensions into their governance practices? Based on previous research in the sector, our main assumptions were that:

(1) NPOs are not fully aware of the external dimensions that might affect their overall performance and,

(2) NPOs are basically using their board members as representatives to legitimate their actions for obtaining resources from their funding bodies [22-24].

\section{Building an Integrative Framework}

The principle according to which sound governance is essential for the health of any type of organization explains the interest of economic and management researchers in this issue over the past few years in all economic sectors. In the neoclassical economic literature [25-27], governance is defined primarily as a means of protecting investors. In this research project we use an approach that focuses more on the stakeholders' perspective and we consider governance as: the set of mechanisms designed to define the powers and influence the decisions of the leaders [28] (our translation). In this approach, governance is not limited to protecting shareholders and earning profits. It can therefore be adapted to the realities of NPOs, which are accountable to a wider variety of stakeholders.

Using this definition, we build a framework that involves monitoring both external and internal dimensions in order to capture the complex environment in which arts and culture NPOs evolve. Figure 1 illustrates the integrative framework and its various dimensions for the specific context of NPOs. From 
this perspective, governance is a central concept that has a direct and indirect influence on an organization's ability to fulfill its mission and remain financially healthy. The direct relationship between governance mechanisms and financial and organizational health comes mostly from the organization's awareness of the importance of the concept of governance and from the concrete actions that reflect this awareness. For example, setting up an efficient and well-oriented board of directors is a concrete way of operationalizing governance. The indirect links between governance and financial and organizational health can be seen in the management policies that organizations adopt.

Figure 1. Governance framework based on dimensions that could impact on organizational and financial health in nonprofit organizations (NPOs).

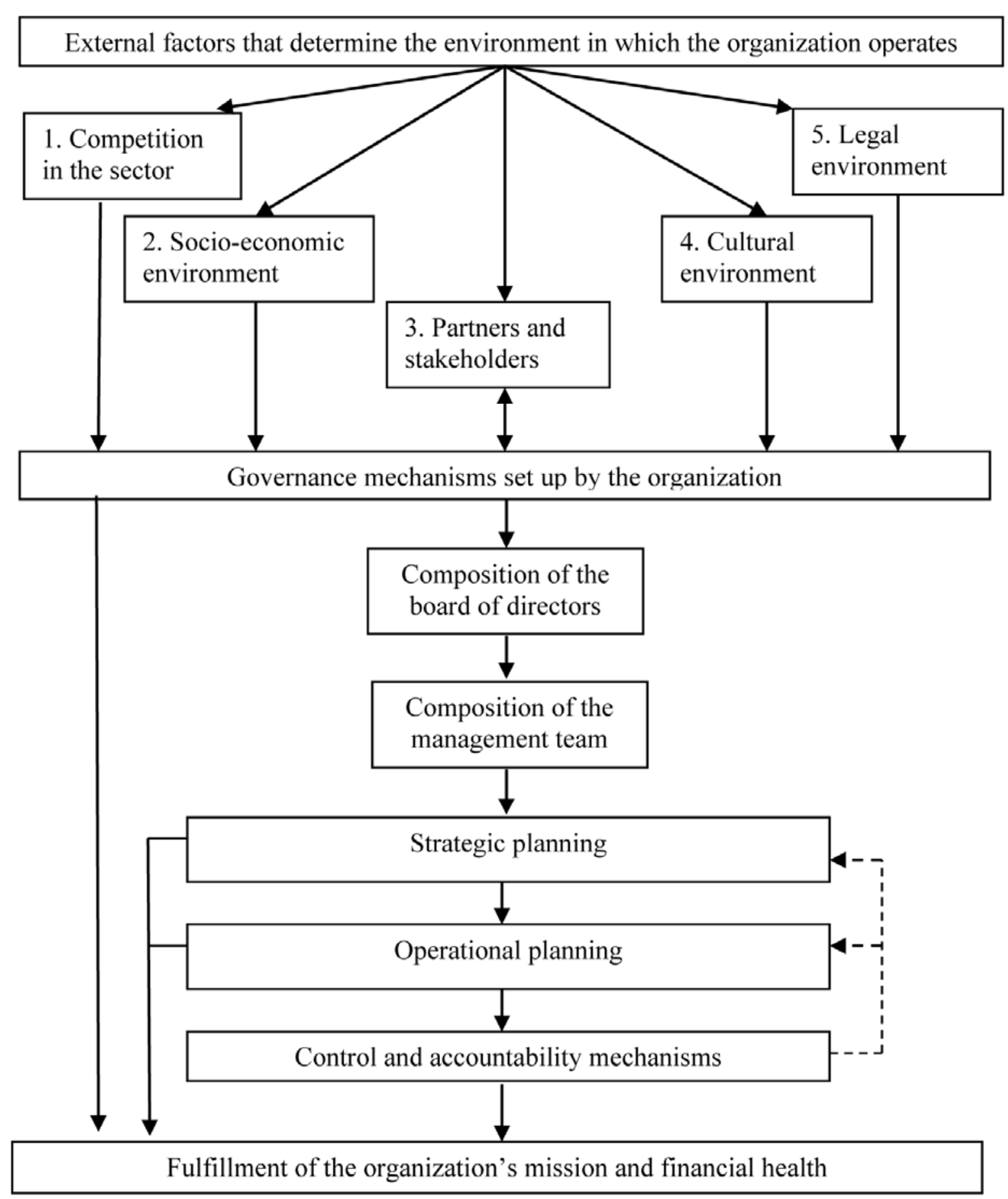




\subsection{Internal Aspects}

In addition to having a board structure that fits the organization's needs, making sure that the board is functional, that board members are representative of the different stakeholders they serve, that board members know what their role and responsibilities are, and that the organization's leaders have a good relationship with the board is essential for sound governance [29,30].

The framework also underscores the importance of setting up a management team that is committed to achieving the goals of the organization. By including top management in the governance framework, we acknowledge the responsibility of the general manager or artistic director for most of the critical events in the organization, a responsibility that is underscored in managerial hegemony theory $[12,13,22]$. For example, building a management team committed to drawing up a strategic plan that reflects the organization's mission and that will eventually gain board approval indirectly ties governance to the organization's financial and organizational health [31]. Throughout the strategic planning process, input from the general manager or artistic director and the board chair is important, because each of these key actors assesses risk from a different perspective, as reflected in stewardship theory [32]. At the end of the process, approval by the board underlines the fact that although strategic planning is mainly the responsibility of top management within the organization, it will eventually become a responsibility that is approved by the principals of the NPO, represented by the board of directors, as suggested by agency theory.

Finally, management control systems connect with sound governance practices. In the arts and culture sector, management control systems need to balance control aimed at monitoring the artistic mission and control aimed at making sure the organization respects its budget constraints. Many observers of this sector are of the opinion, rightly or wrongly, that the financial dimension often takes on too much importance in the evaluation of an organization's performance, at the expense of the artistic dimension. This opinion is reflected in a variety of studies conducted through interviews, case studies and consultation work for donor agencies [23,33-37].

\subsection{External Aspects}

Figure 1 also demonstrates that governance should take into account a number of external dimensions found in the organization's environment. In our opinion, the differences between for-profit corporations and NPOs in terms of governance are significant. Because of their nonprofit status, and because their mission is expressed in cultural, artistic and social terms rather than in economic terms, NPOs must deal with external contingencies in their own way [38]. We argue that, among these contingencies, external dimensions such as market competition and competition for funding are crucial for the future of the organization. The fact that there is fierce competition among NPOs for financial resources, as explained by resource dependence theory $[39,40]$, means that another competitive dimension must be taken into account in their governance [24].

The same could be said for the socio-economic conditions prevailing in the organization's environment. Arts and culture NPOs are vulnerable in times of economic downturn, because they depend heavily on external sources of funding, as shown recently by various reports during the global financial crisis [41]. Also, the cultural climate in which the organization has evolved needs to be monitored. The 
aging population, the place of arts and culture in educational programs, and the increased proportion of immigrants in various markets are all aspects that warrant attention. The legal environment that constrains NPOs - for example, tax requirements, laws governing employee health and safety — should also be overseen by the management teams at NPOs. Although managers can have only a modest influence on these external contingencies, we argue that systematic monitoring of the contingencies should be part of the organization's governance practices. Through such systematic monitoring, NPO managers can quickly become aware of any change in their environment and can react to threats or opportunities as soon as they arise.

Furthermore, management must have a good sense of the nature of its relations with stakeholders. Does management believe it can influence an important stakeholder such as a donor, or is the relationship hierarchical, primarily involving board members? In Figure 1, the bi-directional arrow between the organization and the stakeholders illustrates that, as opposed to the other external contingencies, the organization has a relationship with the stakeholders [42]. In many instances, the nature of this relationship will allow NPO managers to influence stakeholders, which is particularly important if one considers the funding agencies. We argue that the ability to appreciate the board's influence on the stakeholders is essential to governance. Table 1 summarizes the differences between for-profit corporations and arts and culture NPOs with respect to taking external factors into account in order to adapt their methods of governance.

Table 1. Comparison of governance in for-profit corporations and NPOs.

\begin{tabular}{cll}
\hline $\begin{array}{c}\text { External } \\
\text { contingencies }\end{array}$ & \multicolumn{1}{c}{ For-profit corporations } & \multicolumn{1}{c}{ NPOs } \\
\hline $\begin{array}{c}\text { Competition in } \\
\text { the sector }\end{array}$ & For-profit corporations compete for customers. & $\begin{array}{l}\text { NPOs compete for both customers and } \\
\text { funding sources. }\end{array}$ \\
\hline $\begin{array}{c}\text { Socio- } \\
\text { economic } \\
\text { environment }\end{array}$ & $\begin{array}{l}\text { Because of their economic power, for-profit } \\
\text { corporations influence the socio-economic } \\
\text { environment in which they operate. }\end{array}$ & $\begin{array}{l}\text { Because of their strong dependence on } \\
\text { external funding, NPOs are influenced } \\
\text { by their socio-economic environment } \\
\text { more than they influence it. }\end{array}$ \\
\hline $\begin{array}{c}\text { Partners and } \\
\text { stakeholders }\end{array}$ & $\begin{array}{l}\text { Governance is aimed primarily at protecting the } \\
\text { interests of shareholders-in particular, } \\
\text { minority shareholders. }\end{array}$ & $\begin{array}{l}\text { The concept of governance must be } \\
\text { adapted to take into account the interests } \\
\text { of a large number of stakeholders, who } \\
\text { often have diverging interests. }\end{array}$ \\
\hline $\begin{array}{c}\text { Cultural } \\
\text { environment }\end{array}$ & $\begin{array}{l}\text { If they make an effort to adapt, for-profit } \\
\text { corporations can perform within a variety of } \\
\text { cultural environments. }\end{array}$ & $\begin{array}{l}\text { NPOs can survive only in cultural } \\
\text { environments that encourage and } \\
\text { value creativity. }\end{array}$ \\
\hline $\begin{array}{c}\text { Legal } \\
\text { environment }\end{array}$ & $\begin{array}{l}\text { Given the scope of the economic interests at } \\
\text { stake, for-profit corporations must meet formal } \\
\text { institutional requirements to ensure } \\
\text { accountability. }\end{array}$ & $\begin{array}{l}\text { The exercise of accountability is } \\
\text { generally less structured in NPOs than in } \\
\text { for-profit corporations. }\end{array}$ \\
\hline
\end{tabular}




\section{Methodology}

\subsection{Background}

A major condition in undertaking the research project was to obtain formal partnership agreements from organizations that were willing to participate. At the beginning of the project, in 2006, we obtained 32 agreements, and one year later, in summer 2007, we obtained 16 additional ones. During the first year of the project we documented the major artistic and financial issues facing these organizations. In all cases, their governance mechanisms appeared to be weak. CEO were considering their board members as less important as their funding bodies [37] and organizations in financial crises were not considering their external environment as important in terms of planning and programming [21]. In order to analyze in a more systematic way the overall environment and its mechanisms, we developed an integrative framework and asked our partners for their reactions with regard to its main governance dimensions.

\subsection{Sample}

To better understand and document the way governance is exercised in arts and culture NPOs and explore the relevance of our two assumptions, we interviewed managers in order to get their opinions on each of its dimension. Our ultimate aim was to make a comparison between the governance practices being implemented and what we viewed as an integrative approach to governance. We used purposive sampling, also referred to as judgment sampling [43], in order to collect data on a set of NPOs that would be representative of arts and culture NPOs of different sizes, in all subsectors and in various municipalities. We conducted interviews with representatives of 44 arts and culture NPOs during spring and fall 2008. The sample is described in Table 2.

Table 2. Description of sample (four descriptive dimensions).

\begin{tabular}{lc}
\hline Discipline (number of NPOs) & 2007 budget (number of NPOs) $*$ \\
\hline Visual arts (7) & $<\$ 500,000(17)$ \\
\hline Dance $(7)$ & $\$ 500,000-\$ 2$ million $(9)$ \\
\hline Museum $(5)$ & \\
\hline Music (9) & $>\$ 2$ million $(14)$ \\
\hline Presenters (dance, theater, music) $(6)$ & $* 4$ NPOs declined to provide data \\
\hline Theater and circus (10) & In financial crisis [44] (number of NPOs) \\
\hline Location (number of NPOs) & Yes (11 organizations) \\
\hline Population $<500,000(19)$ & No (23 organizations) \\
\hline Population 500,000 or over $(25)$ &
\end{tabular}

Note: * 10 NPOs declined to answer see [45].

\subsection{Data Collection}

We interviewed a manager (or the CEO) from each organization. In our research process, conducting a face-to-face interview with a manager or CEO was important because this approach allowed us to obtain the greatest amount of information from the best informed person regarding governance mechanisms [12,13]. According to Herman and Heimovics [13]: 
Board members are, in general, highly dependent on chief executives for information and expertise; chief executives frequently have a greater stake (that is, a career) in, and identification with, the organization [13] (p. 168).

We therefore made the choice to concentrate on CEOs, because we were, for the first time, exploring the relevance of the dimensions of the integrative framework.

During the interviews, which were recorded and lasted between 60 and 90 minutes, respondents were asked to comment on four dimensions of our framework:

- How they monitored the external dimensions (each of the five dimensions) that could have an impact on their organization.

- How they perceived their relationship with stakeholders - as a partnership or as hierarchical in nature - with a particular focus on their relationship with funding agencies.

- How they proceeded with respect to their strategic and operations planning, including mission statement, safeguarding of assets, human resources management, budgeting and financial control, and performance measurement.

- How they saw their board members as fulfilling their role.

\subsection{Data Analysis}

Analysis of the interview transcripts was conducted by two independent researchers. We used this approach to ensure consistency of results. Each researcher scored the responses on a five-point scale (see Table 3), for the purpose of categorizing each organization with respect to governance. In cases of a scoring discrepancy, the two researchers engaged in discussion in order to come to an agreement on the classification.

Table 3. Scale analysis.

\begin{tabular}{cl}
\hline Scale & \multicolumn{1}{c}{ Description } \\
\hline $\mathbf{- 2}$ & The interviewee has nothing to say about or shows no interest in the controlled factor. \\
$\mathbf{- 1}$ & $\begin{array}{l}\text { The interviewee identifies one or two elements, indicating limited knowledge about or interest in } \\
\text { the controlled factor. }\end{array}$ \\
\hline $\mathbf{0}$ & $\begin{array}{l}\text { Generally, the interviewee shows an interest in the controlled factor but does not support his/her } \\
\text { comments. }\end{array}$ \\
\hline $\mathbf{1}$ & $\begin{array}{l}\text { The interviewee identifies a number of elements, indicating a general understanding of the } \\
\text { controlled factor. }\end{array}$ \\
$\mathbf{2}$ & $\begin{array}{l}\text { In addition to identifying a number of elements, indicating a general and in-depth understanding } \\
\text { of the controlled factor, the interviewee gives examples of how these impact on the organization } \\
\text { and how it adjusts to external factors. }\end{array}$ \\
\hline
\end{tabular}

The score presented in the next section are the average scores of the scales. In the analysis process, we examine the data using different characteristics of the sample: (1) for the 44 organizations, (2) by size of population, (3) by discipline, (4) and finally considering whether or not the organization is in financial crisis.

To present results that are relevant and not redundant, we put emphasis on data that reveals significant evidence about the dimensions of the framework. 


\section{Results}

\subsection{External Dimensions}

We collected information on how managers monitored five external components: (1) competition in the sector, (2) socio-economic environment, (3) partners and stakeholders, (4) cultural environment, and (5) legal environment. The first and third components warrant specific comment.

\subsection{Competition}

Interviewees told us that there were two dimensions on which they competed with other NPOs. First, there was competition for funding, from both public and private sources, across the art and culture sector. Second, although there may have been competition with regard to the artistic products on offer, respondents felt that their industry was characterized by a sense of cooperation at the level of the artistic product. The following two quotes [46] sum up the opinions expressed by a majority of respondents.

- On competition: Our business becomes more complicated when there's money available. I wouldn't go so far as to say that we compete madly for small amounts, but when money is involved competition increases sharply. When a new source of funding becomes available, we're all on our guard and start claiming that we should get it because we're really good.

- On cooperation: Competition exists in the mind of the public, not in our mind. In our industry, we act much more as if we were complementary to each other than as if we were competing against each other.

In line with these quotes, Table 4 shows that $70 \%$ of respondents sense that there is competition for funding within the industry. On the other hand, $49 \%$ sense that there is cooperation rather than competition among their artistic peers with respect to the artistic product [47]. Several respondents told us that cooperation within the community serves to improve the quality of the artistic product in their subsector.

As a complement of information, when analyzing the results by discipline, $67 \%$ of theaters and circuses sense a higher level of competition with regard to artistic products.

Table 4. Competition/Cooperation dimensions (total sample).

\begin{tabular}{cccc}
\hline & Average scores & Competition (\%) & Cooperation (\%) \\
\hline Funding sources & 0.21 & 70 & 21 \\
\hline Artistic considerations & 1.07 & 49 & 49 \\
\hline
\end{tabular}

\subsection{Socio-Economic, Political, Cultural and Legal Aspects}

According to the respondents, the socio-economic impact of their decision (financial position of the government, economic conditions) was only loosely monitored [45]. For the entire sample, interviewees said they were vaguely aware of economic issues (0.25). Looking at the results by discipline, we find that museums $(-0.71)$ and dance companies $(-0.86)$ are the least concerned with economic issues in their monitoring of the environment. 
In contrast, when looking at the political aspect (namely, relations with funders, private donors, the community), managers overall display relatively strong awareness (1.02) of political issues: For our organization to be well positioned at the national and international levels, we need political support. We would never have access to major funding without political support.

By discipline, museums (1.80) and the music sector (1.33) show the greatest interest on this factor. Museums establish direct links on how the political issues can affect their activities.

Turning to the cultural dimension (namely, tendencies of diffusion in the media and ethnic social fabric), managers again display relatively strong awareness (0.86) of cultural issues. By discipline, we observe that, as with political issues, museums (2.00) and the music sector (1.33) show a strong interest in issues within their cultural environment. Museums establish direct links on how cultural issues can affect their activities.

Finally, with respect to the legal dimension, managers display some awareness $(0.30)$ of legal issues. By discipline, dance $(-0.43)$ and museums $(-0.40)$ score the lowest on this factor, demonstrating a very superficial interest in the legal dimension.

If we split the sample by geographic area (municipalities with a population of under 500,000 or 500,000 or more), the results reveal interesting differences (Table 5).

The political dimension has the highest score, regardless of area. However, with the exception of the legal dimension, managers in smaller municipalities speak much more about external dimensions of their environment and are concerned about how to monitor each. As a complement of information, there is no significant difference, regarding external dimensions, when we split our results between organizations in crisis and those not in crisis (Table 6). However, it is worth noting that organizations facing a financial crisis seems slightly more aware of external dimensions than organizations not in crisis.

Table 5. External dimensions, by geographic area (average scores).

\begin{tabular}{ccccc}
\hline Population & Economic & Political & Cultural & Legal \\
\hline Population $<500,000$ & 0.47 & 1.58 & 1.26 & 0.21 \\
\hline Population 500,000 or more & 0.08 & 0.60 & 0.56 & 0.36 \\
\hline
\end{tabular}

Table 6. External dimensions (crisis or not crisis) (average scores).

\begin{tabular}{ccccc}
\hline In a crisis situation & Economic & Political & Cultural & Legal \\
\hline No $(23)$ & 0.17 & 0.87 & 0.70 & 0.35 \\
\hline Yes $(11)$ & 0.36 & 1.09 & 1.36 & 0.36 \\
\hline
\end{tabular}

Tables 5 and 6 also confirm that the economic and legal dimensions are not of great interest to arts and culture NPOs in Quebec. One manager told us: Other than poverty, socio-economic factors have no impact at all on our organization. Another confirmed this position: We don't pay attention to socioeconomic issues ... We're trying to sell our product whatever the economic trend is; we can't do anything about it anyway. These two quotes sum up the opinions of our respondents with regard to economic and legal components. 


\subsection{Relationship with Stakeholders}

In order to capture the nature of relations between managers and major stakeholders (see the bi-directional arrow in Figure 1, we asked managers if they felt that (1) funders are in charge, (2) funders have significant influence, (3) the partnership is balanced, (4) NPOs have significant influence over funders, or (5) NPOs are in charge. The majority of respondents said that funders have significant influence (choice \#2), and this result is generalized across the sample (i.e., choice \#2 prevails irrespective of artistic sector, geographic area or whether the NPO is in crisis). One respondent said, I'd like to move higher on your [collaboration] scale, but, realistically, they [the funding bodies] have the authority. Another commented, I really have to be nice to them [funding bodies], otherwise...

Finally, we asked respondents to assess their own influence on dimensions external to their organization. The proportion of respondents who believed they had influence on the various dimensions of their environment is shown in Table 7. Linking the results presented in Tables 5 and 6 , we conclude that managers are less careful in their monitoring of those dimensions where they have no influence (socioeconomic and legal).

Table 7. NPOs' perception of their influence on external dimensions.

\begin{tabular}{ccccccc}
\hline $\begin{array}{c}\text { Total } \\
\text { Sample }\end{array}$ & $\begin{array}{c}\text { Competition } \\
\mathbf{( \% )}\end{array}$ & $\begin{array}{c}\text { Socio-economic } \\
\mathbf{( \% )}\end{array}$ & $\begin{array}{c}\text { Political } \\
\mathbf{( \% )}\end{array}$ & $\begin{array}{c}\text { Cultural } \\
\mathbf{( \% )}\end{array}$ & $\begin{array}{c}\text { Legal } \\
\mathbf{( \% )}\end{array}$ & $\begin{array}{c}\text { Funders } \\
(\mathbf{\%})\end{array}$ \\
\hline 44 NPOs & 30 & 20 & 39 & 45 & 5 & 34 \\
\hline
\end{tabular}

\subsection{Internal Dimensions}

In this section, we first report on how respondents perceive their monitoring of four management activities that are part of our proposed governance framework and then look at how they see board members as fulfilling their role. Definitions of these four internal dimensions are presented in Table 8 .

Table 8. Definitions of internal dimensions.

\begin{tabular}{cl}
\hline Dimension & \multicolumn{1}{c}{ Definition } \\
\hline Mission & $\begin{array}{l}\text { The organization is able to clearly outline its mission or the performance } \\
\text { indicators that will allow it to do so. }\end{array}$ \\
\hline $\begin{array}{c}\text { Strategic } \\
\text { planning }\end{array}$ & $\begin{array}{l}\text { The organization conducts strategic planning and an external consultant or board } \\
\text { member designs or revises the process. Reviews/evaluations are made. The } \\
\text { organizational plan is based on the strategic planning process, not the other way } \\
\text { around. }\end{array}$ \\
\hline $\begin{array}{c}\text { Operational } \\
\text { planning }\end{array}$ & $\begin{array}{l}\text { The organization is able to outline its production cycle, give examples of } \\
\text { planning work, and follow up on/evaluate the production cycles. The } \\
\text { organizational plan is based on the strategic planning process. }\end{array}$ \\
\hline $\begin{array}{c}\text { Control and } \\
\text { accountability }\end{array}$ & $\begin{array}{l}\text { Organization chart, job descriptions, employee evaluations, financial control } \\
\text { (budgeted/actual), internal control (double signature, bank reconciliation, etc.). }\end{array}$ \\
\hline
\end{tabular}




\subsection{Strategic and Operations Planning}

Using the same scale as that described in Table 3, Table 9 indicates that the managers have a good knowledge of their mission (1.20) regardless of artistic sector, size, location or financial situation (in crisis/not in crisis). Globally, managers have an interest in strategic planning (0.23) but do not support this position with convincing arguments. Looking at the data by discipline, visual arts $(-0.86)$ have a mitigated interest in strategic planning but theaters and circuses $(0.90)$ have a good understanding of the concept.

Table 9. Monitoring of internal dimensions: Total sample and by discipline (average scores).

\begin{tabular}{lcccc}
\hline \multicolumn{1}{c}{ Discipline } & Mission & Strategic plan & Operational plan & Control and accountability \\
\hline Visual arts (7) & 0.86 & -0.86 & 0.86 & 0.57 \\
\hline Dance (7) & 1.57 & 0.29 & 0.57 & 0.86 \\
\hline Museum (5) & 1.60 & 0.00 & 1.00 & 1.40 \\
\hline Music (9) & 1.00 & 0.33 & 1.11 & 1.56 \\
\hline Presenters (6) & 0.83 & 0.33 & 0.83 & 1.17 \\
\hline Theater and circus (10) & 1.40 & 0.90 & 1.20 & 1.40 \\
\hline Total sample (44 NPOs) & 1.20 & 0.23 & 0.95 & 1.18 \\
\hline
\end{tabular}

Several quotes illustrate the degree to which strategic planning is taken seriously by the organizations surveyed:

- Strategic planning seems to be a trend ... In fact, it consists mainly of summing up the annual objectives, the means to achieve them and the deadlines. I'm solely responsible for all this.

- We do have short- and long-term objectives, but we have no formal plan. We achieve our objectives anyway but we should probably draw up a formal plan.

- We no longer have a strategic plan, because the last one we did is not current. The board gives us a master plan, which is more global and institutional. The "strategic" dimensions have become more operational.

- We've been working on our strategic plan for the past year and a half. We're about to adopt it, and it's going to completely change the orientation of our organization. We aim to become financially responsible, respect budget constraints, hire young, local talent, and offer extraordinary products.

As the results suggest, for all NPOs operational planning is a more familiar concept, which sometimes get confused with strategic planning. However, operational planning appears to be less important for managers in the dance sector than for those in other sectors. Overall, managers have a good knowledge of controls and accountability (1.18). By discipline, we note less interest within the visual arts sector (0.57).

\subsection{Role of Board Members}

With respect to board composition, under Quebec law the board of an NPO can include internal members who are managers (general or artistic) or employees. Although this situation is less prevalent now than it was in the past, there are still NPOs whose artistic director is the founder and also sits on the 
board. In a more global context, a number of laws (e.g., Sarbanes-Oxley) stipulate that the majority of the board be made up of external members. Since this is a crucial issue, we chose to address it in our empirical study.

We were also interested in an element that is of interest to many researchers in the field of nonprofit governance: the importance of having board members compensate for the lack of business expertise within an organization. Hence, we asked respondents if they believed their board members were fulfilling a role in either accountability or consultancy. Finally, other researchers have found that board members and managers have difficulty understanding their respective roles and duties. We also considered this aspect in our interview grid. Table 10 summarizes the aspects of governance studied.

Table 10. Aspects of governance covered in interviews.

\begin{tabular}{ll}
\hline \multicolumn{1}{c}{ Aspect of governance } & \multicolumn{1}{c}{ Description } \\
\hline Composition of the board & Majority of internal members or Majority of external members \\
\hline \multirow{2}{*}{ Roles of the board } & $\begin{array}{l}\text { (a) Accountability: approval of budgets and financial statements. } \\
\text { (b) Consultancy: the organization draws from the professional expertise of } \\
\text { its board members, who are recruited for that purpose; the board monitors } \\
\text { external contingencies. }\end{array}$ \\
\hline Understanding of roles & $\begin{array}{l}\text { Oversight, strategic direction, committee business, fundraising, general } \\
\text { understanding of duties. }\end{array}$ \\
\hline
\end{tabular}

Again using the scale presented in Table 3, Table 11 shows that managers seem to have a basic understanding of the roles played by board members (0.18). They tend to believe that accountability $(0.55)$ is an important trait for board members but not consultancy $(-0.03)$. The visual arts sector shows the lowest scores (all under zero) for the three elements. It is interesting to note that the visual arts are the only discipline where internal members form the majority of the board (57\%).

Respondents also appear to be more satisfied with the contribution of external members than with that of internal members: It is due to the contribution of members from the business community that our organization has been able to build a more professional structure; unfortunately, in Quebec there does not seem to be a tradition of involvement on the part of the business community.

Table 11. Understanding of governance: Total sample and by discipline.

\begin{tabular}{cccccc}
\hline Discipline & $\begin{array}{c}\text { Accountability } \\
\text { Role } \\
\text { (average score) }\end{array}$ & $\begin{array}{c}\text { Consultancy } \\
\text { Role } \\
\text { (average score) }\end{array}$ & $\begin{array}{c}\text { Understanding } \\
\text { of role } \\
\text { (average score) }\end{array}$ & $\begin{array}{c}\text { Board: } \\
\text { external } \\
\text { majority } \\
\mathbf{( \% )}\end{array}$ & $\begin{array}{c}\text { Board: } \\
\text { internal } \\
\text { majority } \\
\mathbf{( \% )}\end{array}$ \\
\hline Visual arts (7) & -0.43 & -0.83 & -0.57 & 43 & 57 \\
\hline Dance (7) & 0.57 & -0.43 & 0.43 & 100 & 0 \\
\hline Museum (5) & 1.00 & 1.00 & 0.20 & 100 & 0 \\
\hline Music (9) & 0.67 & 0.33 & 0.44 & 89 & 13 \\
\hline Presenters (6) & 1.00 & 0.20 & 0.00 & 100 & 0 \\
\hline Theater and circus (10) & 0.60 & -0.11 & 0.40 & 60 & 30 \\
\hline Total sample (44 NPOs) & 0.55 & -0.03 & 0.18 & 80 & 19 \\
\hline
\end{tabular}




\subsection{Role of Board Members during a Financial Crisis}

If we divide our sample between NPOs in financial crisis and those not in crisis, the findings are interesting. Regarding the internal dimensions, NPOs not in crisis score higher on monitoring of mission, strategic plan and operational plan. Those in crisis score higher on control and accountability. This result appears to be a normal reaction when financial problems occur. It seems that board members become more engaged in both roles when the NPO is in crisis. Table 12 shows that managers perceive board members as fulfilling their roles to a greater extent when the NPO is in crisis.

Table 12. Internal dimensions and governance when in crisis/not in crisis (average scores).

\begin{tabular}{lcc}
\hline \multirow{2}{*}{ Internal dimensions and governance } & \multicolumn{2}{c}{ In a crisis situation } \\
\cline { 2 - 3 } & No (23) & Yes (11) \\
\hline Mission & 1.57 & 0.91 \\
\hline Strategic plan & 0.52 & 0.18 \\
\hline Operational plan & 1.09 & 0.82 \\
\hline Control and accountability & 1.00 & 1.36 \\
\hline Accountability role (average score) & 0.48 & 1.00 \\
\hline Consultancy role (average score) & -0.09 & 0.27 \\
\hline Understanding of role (average score) & 0.35 & 0.18 \\
\hline Board: external majority (\%) & 70 & 100 \\
\hline Board: internal majority (\%) & 26 & 0 \\
\hline
\end{tabular}

The following quotes illustrate the different perceptions of the role that board members play in an organization not in crisis compared to that played in an organization in crisis:

- Organization not in crisis: The board plays a leading role in the overall orientation, but I assume day-to-day responsibility ... I don't want board members invading my day-to-day work.

- Organization in crisis: Board members have been heavily involved in managing the crisis we've been going through the past two years ... The board shares responsibility for what is going on in our organization and helps in finding solutions. We've been going through a very tough time, and we've always had the support of our board. Although they don't work here, board members frequently meet, discuss and share responsibility for the decisions we make.

\section{Discussion}

The main objective of this research was to document the governance practices in different types of arts and culture NPOs to document if managers are taking into account the recent developments in the literature on what might be view as "good" governance practices (dimensions of the framework). We would have expected that monitoring all the dimensions included in our integrative framework would help managers of NPO avoid financial crises by being more aware of the various "market and management" dimensions that can affect their performance.

We find that managers monitor external dimensions that are directly connected to their mission. The socio-economic and legal dimensions are not well monitored by arts and culture NPOs, perhaps because managers believe they cannot control these dimensions (see Table 5). Competition (including 
competition for funding), cultural factors and political relations are variables that are taken into consideration by a majority of leaders. The fact that museums and music organizations are even more aware of cultural factors and political relations is certainly an evidence of their dependence to funders. Public funding represents for museums over 50\% of their revenues [48] and for music organizations over $40 \%$ of their revenues [49]. The resource dependence theory is also confirmed by respondents regarding who has the power in the relationship: Funders or NPOs. They perceive funders as having a significant influence, meaning that even if arts and culture managers could influence the decisions of funders, it is the latter that have the bargaining power. It is therefore less surprising to observe, in our sample, that there is no significant difference between organizations not in crisis and the ones in crisis regarding external dimensions (see Table 6). The main focus of arts and culture NPOs managers facing a financial crisis is on convincing funders to give additional funds. These results are in line with a previous longitudinal research done with four organizations facing a financial crisis. Their first move was to beg for an emergency grant to their respective funding body [21].

In this project, our first assumption is then partially confirmed. We proposed that arts and culture NPOs are not fully aware are of the external dimensions that might affect their overall performance. It seems that socio-economic and legal dimensions are not taken into account even in organizations not in crisis. In a global context where public and private funds are less available, where rules and regulations are becoming tighter, we still believe, like Ostrower and Stone [5] that these dimensions and maybe others “... deserve more conceptual attention as well as more direct inclusion as variables that influence board practices" [5] (p. 923). The present research cannot link NPOs performance to the monitoring of these dimensions but it would be a good research opportunity to study the governance practices in performing NPOs, using our proposed integrative framework.

Regarding the internal dimensions, it is interesting to note that arts managers are not clear on strategic planning even though much emphasis has been placed, over the past decade, on the importance of this "managing tool" [50]. Connecting this result with the weak scores on the counseling role that could be played by board members suggests an opportunity to have board members help managers better understand the benefits of that tool. Stewardship theory, according to which board members and managers share common interests in adding value to executive decisions [1], might provide the hindsight needed to improve governance in arts and culture NPOs. Under this theory, the main function of the board is not to control and watch the manager but to work and support management for the best interest of the organization.

Finally, in terms of how managers see board members as fulfilling their role, respondents believe that external board members have a better understanding than internal members of the functions they need to perform. This subsample is quite small (7 NPOs as per Table 10), but it is still a notable trend, in our view. Also, board members appear to become more vigilant in times of crisis, a result that is consistent with findings reported by Wood [51], Mordaunt and Cornforth [52], and Reid and Turbide [21]. Board members' implications are cyclical and, in times of crisis, agency theory (compliance model) takes the lead over managerial hegemony theory (rubber-stamp model).

It seems that our second assumption is also partially confirmed. We proposed that NPOs are basically using their board members as representatives to legitimate their actions for obtaining resources from their funding bodies. According to managers interviewed, board members are doing more than acting as representatives. They understand their role as being mainly in charge of accountability and control. 
These results are showing a certain evolution. In an earlier research, we found that arts and culture NPOs managers were not at all convinced of the value added of board members [37]. Now, managers feel that board members are more engaged and that there is some contributions made by external members. Our results are also showing that board members of organizations not in crisis are aware of the "planning" internal dimensions such as the mission, the operational and the strategic plan.

\section{Conclusions}

The aim of this paper was to propose and explore empirically the relevance of an integrative framework of governance in arts and culture NPOs. Our framework was inspired by different theoretical perspectives and considers external and internal dimensions of governance, reflecting recent developments in the nonprofit governance literature. This study suggests that internal dimensions are more closely monitored by NPO leaders than external dimensions. We also find that board members are seen as playing an accountability role and that their consultancy role is less solicited. Our results are not showing significant differences between organization not in crisis and the ones in crisis, except maybe for the fact that those not in crisis seem to be more alert on dimensions such as monitoring organizational or financial problems, using a strategic or an operational plan. Nevertheless, we still believe that there is more research to be done using that integrative framework in order to make NPOs managers and their board members more sensitive to the complexity of their environment and to enrich their contributions to the well-being of the field.

Finally, use of different theoretical perspectives appears to afford a richer approach to governance in action, and our findings indicate the co-existence of three different perspectives: resource dependence theory, managerial hegemony theory and agency theory.

\section{Acknowledgments}

We acknowledge research support from the Community-University Research Alliances (CURA), funded by the Social Sciences and Humanities Research Council of Canada (SSHRC).

\section{Author Contributions}

For this paper, Johanne Turbide put $60 \%$ of the research design, the data collection and analysis and the writing of the paper. Claude Laurin's contribution is $40 \%$. We wish to thank Veronica Zuniga-Salas and Christine Harel for their comments. All authors have read and approved the final manuscript.

\section{Conflicts of Interest}

The authors declare no conflict of interest.

\section{References and Notes}

1. Cornforth, C., Ed. The Governance of Public and Non-profit Organisations: What Do Boards Do? Routledge: Oxford, UK, 2005.

2. Miller, J.L. The Board as a Monitor of Organizational Activity: The Applicability of Agency Theory to Nonprofit Boards. Nonprofit Manag. Leadersh. 2002, 12, 429-450. 
3. Miller-Millesen, J.L. Understanding the Behavior of Nonprofit Boards of Directors: A Theory-Based Approach. Nonprofit Volunt. Sect. Q. 2003, 32, 521-547.

4. Stone, M.M.; Ostrower, F. Acting in the Public Interest? Another Look at Research on Nonprofit Governance. Nonprofit Volunt. Sect. Q. 2007, 36, 416-438.

5. Ostrower, F.; Stone, M.M. Moving Governance Forward: A Contingency-Based Framework and Data Application. Nonprofit Volunt. Sect. Q. 2009, doi:10.1177/0899764009338962.

6. Malenfant, R. La gouvernance stratégique d'un organisme sans but lucratif: sa dynamique, ses composantes; Éditions D.P.R.M.: Saint-Nicolas, QC, Canada, 1999. (In French)

7. Sawhill, J.; Williamson, D. Mission Impossible? Measuring Success in Nonprofit Organizations. Nonprofit Manag. Leadersh. 2001, 11, 371-386.

8. Speckbacher, G. The Economics of Performance Management in Nonprofit Organizations. Nonprofit Manag. Leadersh. 2003, 13, 267-281.

9. Ostrower, F.; Bobowick, M.J. Nonprofit Governance and the Sarbanes-Oxley Act. Available online: http://www.urban.org/publications/311363.html (accessed on 6 November 2014).

10. Brown, W.A.; Guo, C. Exploring the Key Roles for Nonprofit Boards. Nonprofit Volunt. Sect. Q. 2010, 39, 536-546.

11. Carver, J. Boards That Make a Difference: A New Design for Leadership in Nonprofit and Public Organizations, 2nd ed; Jossey-Bass: San Francisco, CA, USA, 1997.

12. Golensky, M. The Board-Executive Relationship in Nonprofit Organizations: Partnership or Power Struggle? Nonprofit Manag. Leadersh. 1993, 4, 177-191.

13. Herman, R.D.; Heimovics, R.D. The Effective Nonprofit Executive: Leader of the Board. Nonprofit Manag. Leadersh.1990, 1, 167-180.

14. Murray, V.; Bradshaw, V.P.; Wolpin, J. Power in and around Nonprofit Boards: A Neglected Dimension of Governance. Nonprofit Manag. Leadersh.1992, 3, 165-182.

15. Bertrand, C.; Turbide, J. Boards in Small NPOs: What about Friendship and Solidarity? Nonprofit Q. 2007, 14, 16-23.

16. Houle, C.O. Governing Boards: Their Nature and Nurture; Jossey-Bass: San Francisco, CA, USA, 1989.

17. Lampel, J.; Lant, T.; Shamsie, J. Balancing Act: Learning from Organizing Practices in Cultural Industries. Organ. Sci. 2000, 11, 263-269.

18. Ostrower, F.; Stone, M.M. Governance: Research Trends, Gaps, and Future Prospects. In The Nonprofit Sector: A Research Handbook, 2nd ed.; Powell, W.W., Steinberg, R., Eds.; Yale University Press: New Haven, CT, USA, 2006; pp. 612-628.

19. Kramer, R. Toward a Contingency Model of Board-Executive Relations. Adm. Soc. Work 1985, 9, $15-33$.

20. This research project, titled Financial Crises in the Arts and Culture Sector: Act Ahead, Don't React, was conducted in 2006 in the Canadian province of Quebec with a grant from the Social Sciences and Humanities Research Council of Canada (SSHRC) under the CURA (Community-University Research Alliance) program. Under this program, researchers work closely with the community they are studying (here, arts and culture NPOs) in order to develop concrete solutions relative to the research questions. 
21. Reid, W.; Turbide, J. Board/Staff Relationships in a Growth Crisis: Implications for Nonprofit Governance. Nonprofit Volunt. Sect. Q. 2012, 41, 82-99.

22. Herman and Heimovics call their approach "board-centered leadership".

23. Voss, Z.G.; Voss, G.B. Exploring the Impact of Organizational Values and Strategic Orientation on Performance in Not-for-Profit Professional Theatre. Int. J. Arts Manag. 2000, 3, 62-76.

24. Tuckman, H.P.; Chang, C.F. How Well Is Debt Managed by Nonprofits? Nonprofit Manag. Leadersh. 1993, 3, 347-361.

25. Bushman, R.M.; Smith, A.J. Financial Accounting Information and Corporate Governance. J. Account. Econ. 2001, 32, 237-333.

26. La Porta, R.; Lopez-de-Silanes, F.; Shleifer, A.; Vishny, R. Investor Protection and Corporate Governance. J. Financ. Econ. 2000, 58, 3-27.

27. Shleifer, A.; Vishny, R.W. A Survey of Corporate Governance. J. Financ. 1997, 52, 737-781.

28. Charreaux, G. Le Gouvernement des Entreprises: Corporate Governance, Théories et Faits; Économica: Paris, France, 1997. (In French)

29. DiMaggio, P.; Useem, M. Cultural Democracy in a Period of Cultural Expansion: The Social Composition of Arts Audiences in the United States. Soc. Probl. 1978, 26, 179-197.

30. Zolberg, V.L. Conflicting Visions in American Art Museums. Theory Soc. 1981, 10, 103-125.

31. Siebart, P. Corporate Governance of Nonprofit Organizations: Cooperation and Control. Int. J. Public Adm. 2005, 28, 857-867.

32. Davis, J.H.; Schoorman, F.D.; Donaldson, L. Toward a Stewardship Theory of Management. Acad. Manag. Rev. 1997, 22, 20-47.

33. Chiapello E. Accounting and Control in Arts Organizations. Presented at Research Seminar, Accounting and Finance Department, London School of Economics, London, UK, 1991.

34. Schuster, J.M. The Performance of Performance Indicators in the Arts. Nonprofit Manag. Leadersh. 1996, 7, 253-269.

35. Turbide, J. Management Accounting Systems and the Exercise of Interpersonal Power in Organizations: Observations from an Accounting Free Zone: The Case of Not-for-Profit Performing Arts Organizations. Ph.D. Thesis, University of Warwick, England, UK, March 1997.

36. Turbide, J.; Hoskin, K. Managing Non-profit Arts Organizations through Management Accounting Systems: Mission Possible? Int. J. Arts Manag. 1999, 1, 68-81.

37. Turbide, J.; Laurin, C. Performance Measurement in the Arts Sector: The Case of the Performing Arts. Int. J. Arts Manag. 2009, 11, 56-70.

38. Euske, K. An Examination of Control Mechanisms in Organizations with Ill-Defined Technology and Output. In Performance Measurement, Evaluation, and Incentives; Bruns, W.J., Jr., Ed.; Harvard Business School Press: Boston, MA, USA, 1992; pp. 245-277.

39. Pfeffer, J.; Salancik, G. The External Control of Organizations: A Resource Dependence Perspective; Harper \& Row: New York, NY, USA, 1978.

40. Gronbjerg, K.A. Understanding Nonprofit Funding: Managing Revenues in Social Services and Community Development Organizations; Jossey-Bass: San Francisco, CA, USA, 1993.

41. Courchesne, A.; Turbide, J. L’Économie des arts en temps de crise. Available online: http://culturemontreal.ca/2009/11/colloque-leconomie-des-arts-en-temps-de-crise/ (accessed on 6 November 2014). (In French) 
42. Because some organizations can influence funders such as funding agencies, the nature of the relationship between the organization and its funders is sometimes perceived more as a partnership than as a hierarchical relationship. It is crucial for an NPO to appreciate the nature of its relationship with donors. Even if some form of partnership is foreseeable, management must never lose sight of the fact that it is accountable to donors first and foremost.

43. Cooper, D.R.; Schindler, P.S. Business Research Methods, 8th ed.; McGraw-Hill Irwin: Boston, MA, USA, 2003.

44. In order to determine whether an organization was in financial crisis, after the interviews (to protect sensitive information), we sent the respondents an e-mail posing two questions: Have you had problems paying salaries or creditors in the past 12 months? Have you requested a special grant or emergency funds in order to honor your regular commitments? If the answer to either question was yes, we considered the organization to be in financial crisis. The total ends up to 34 because 10 organizations refuse to answer the question.

45. Note that the interviews were conducted before the global financial recession in October 2008.

46. All of the comments by respondents were expressed in French and have been translated by the authors.

47. To determine perceived competition or cooperation, we asked respondents if they sensed competition or cooperation regarding (a) funding, and (b) artistic considerations. The percentages represent the results for these two questions.

48. Institut de la statistique du Québec, Observatoire de la culture et des communications du Québec, Enquête auprès des établissements du patrimoine, 2005. (In French)

49. Institut de la statistique du Québec, Observatoire de la culture et des communications du Québec, Principal statistics on music production organizations funded by the Conseil des arts et des lettres du Québec, Québec, 2007-2008 to 2011-2012. (In French)

50. Daigle, L.; Rouleau, L. Strategic Plans in Arts Organizations: A Tool of Compromise between Artistic and Managerial Values. Int. J. Arts Manag. 2010, 12, 13-30.

51. Wood, M. Is Governing Board Behavior Cyclical? Nonprofit Manag. Leadersh. 1992, 3, 139-163.

52. Mordaunt, J.; Cornforth, C. The Role of Boards in the Failure and Turnaround of Nonprofit Organizations. Public Money Manag. 2004, 24, 227-234.

(C) 2014 by the authors; licensee MDPI, Basel, Switzerland. This article is an open access article distributed under the terms and conditions of the Creative Commons Attribution license (http://creativecommons.org/licenses/by/4.0/). 